\title{
Socioeconomic determinants of prostate-specific antigen testing and estimation of the prevalence of undiagnosed prostate cancer in an elderly Polish population based on the PolSenior study
}

Andrzej Prajsner ${ }^{1}$, Jerzy Chudek ${ }^{2,3}$, Aleksandra Szybalska ${ }^{4}, K_{\text {Karolina Piotrowicz }}^{5}$, Jan Zejda ${ }^{6}$, Andrzej Więcek ${ }^{3}$; PolSenior Study Group

\author{
${ }^{1}$ Department of Urology, Medical Faculty, Medical University of Silesia, Katowice, Poland \\ 2Department of Pathophysiology, Medical Faculty, Medical University of Silesia, \\ Katowice, Poland \\ ${ }^{3}$ Department of Nephrology, Transplantation and Internal Medicine, Medical Faculty, \\ Medical University of Silesia, Katowice, Poland \\ ${ }^{4}$ International Institute of Molecular and Cell Biology, Warsaw, Poland \\ ${ }^{5}$ Department of Internal Medicine and Gerontology, Jagiellonian University Medical \\ College, Krakow, Poland \\ ${ }^{6}$ Department of Epidemiology, Medical Faculty, Medical University of Silesia, \\ Katowice, Poland
}

Submitted: 1 December 2014

Accepted: 5 March 2015

Arch Med Sci 2016; 12, 5: 1028-1035

DOI: 10.5114/aoms.2015.55271

Copyright (C) 2016 Termedia \& Banach

\section{Abstract}

Introduction: Socioeconomic determinants of prostate-specific antigen (PSA) testing and prevalence of undiagnosed prostate cancer (PCa) in the Polish population are poorly understood. The aim of this study was to identify factors associated with PSA testing in elderly Polish men, and estimate the size of the population at risk of PCa related to PSA non-testing.

Material and methods: We analyzed questionnaire-derived data concerning PSA testing, obtained in 2567 elderly and 332 younger (age: 55-59) participants of the population-based PolSenior study. Additionally, PSA was measured in 2414 subjects.

Results: The PSA had previously been tested in $41.2 \%$ of elderly and in $24.8 \%$ of younger participants. Non-smoking status $(\mathrm{OR}=2.06, p<0.001)$, higher personal income $(\mathrm{OR}=1.56, p<0.001)$, better education $(\mathrm{OR}=1.49, p=0.001)$, previous white-collar work $(\mathrm{OR}=1.37, p=0.005)$, alcohol abstinence $(\mathrm{OR}=$ $1.28, p=0.02)$, married status ( $O R=1.24, p=0.04)$, dependence in Instrumental Activities of Daily Living (IADL) but not in Activities of Daily Living $(\mathrm{ADL})(\mathrm{OR}=0.65, p<0.001)$, and dependence in $\mathrm{ADL}(\mathrm{OR}=0.55, p<0.001)$ were independent predictors of previous PSA testing in elderly participants. There were 31 elderly previously treated for PCa (calculated standardized prevalence: 935 per 100,000 elderly population). The PSA levels $>4 \mathrm{ng} / \mathrm{ml}$ were found in $12.8 \%$ of $65-74$-year-old and $4.5 \%$ of $55-59$-year-old previously non-tested participants. We calculated the standardized prevalence rate of undiagnosed PCa as approximately 1370 and 2352 cases per 100,000 population aged 55-59 and 65-74 years, respectively.

Conclusions: In Poland, $58.8 \%$ of elderly men have never had PSA tested. These were less likely to be functionally independent, married, better educated, non-smokers or to have previous office employment or higher than average personal income. Our data suggest substantial underdiagnosis of prostate cancer among Polish men.

Key words: epidemiology, prostate cancer screening, prostate-specific antigen, screening.

\section{Corresponding author:}

Prof. Jerzy Chudek MD, PhD

Department

of Pathophysiology

Medical University of Silesia

18 Medykow St

40-752 Katowice, Poland

Phone/fax: +48 322526091

E-mail: chj@poczta.fm 


\section{Introduction}

Prostate cancer $(\mathrm{PCa})$ is the most common cancer affecting men in the developed countries [1, 2]. In Poland, PCa accounted for $14.4 \%$ of all cancer cases among men in 2011, making it the second most common cancer in males. The lifetime risk for PCa in the United States is estimated at $15.9 \%$, and the risk of death is $2.3 \%$ [1]. The expected survival in treated patients is at least 10 to 15 years [3].

The highest incidence of PCa has been reported in Europe (111 cases per 100,000 men per year) and North America (101 cases per 100,000 men per year) [1]. According to the report of the Polish National Cancer Center, morbidity from PCa (the standardized incidence rate) almost doubled from $18.3 / 100,000$ in 1999 to $36.1 / 100,000$ in 2012 , with the highest incidence among men aged 70-74 years (2122/100,000 in 2012) [4]. By 2020 the incidence of PCa among elderly Polish men is expected to increase by $30 \%$ and reach approximately 13,000 cases annually [5]. It is mostly due to screening measures (e.g. digital rectal examination (DRE) and prostate-specific antigen (PSA) testing) and more frequent prostate biopsies in patients with elevated PSA levels (> $4 \mathrm{ng} / \mathrm{ml}$ for Caucasians).

Only one published study has analyzed PSA testing in Poland. This was a large population-based survey of 28 European countries (including Poland) conducted in 2006 (Eurobarometer 66.2 "Health in the European Union"). It found that only $22 \%$ of men aged 40 years and older had had a PSA test in the previous 12 months, with large regional variability (5-43\%) [6]. Age, education level, marital status, smoking habit, and socio-economic status were associated with the likelihood of screening. The highest PSA testing uptake was among men aged 70 years or more. Unfortunately, the PSA test lacks sensitivity and specificity for early PCa [7]. Therefore, benefits of PSA screening in the very elderly are uncertain, and may not outweigh the harms, due to the risk related to unnecessary biopsies, overdetection, and overtreatment [8].

Low utilization of PSA and DRE testing recommended by the Polish Association of Urology in line with European Association of Urology (EAU) in men aged $40-75$ years [9] results in late diagnosis of symptomatic PCa (locally advanced and/ or metastatic disease) and palliative treatment. However, a recently performed review of the available literature found strong evidence that for PSA-based screening the benefits may outweigh harms in men aged 55-69 years [10].

On the other hand, the increasing life expectancy results in a growing population older than 75 years with very good health, who are likely to live at least another 10 years. This group of men may benefit from routine PSA screening, according to American guidelines [11].
The recently completed PolSenior study included information on PSA testing in a large representative elderly Polish population. Data from the PolSenior study allow analysis of the rate of PSA testing in relation to a much wider range of determinants than previous studies.

The aim of this study was to identify factors associated with PSA testing in elderly Polish men and estimate the size of the population at risk of $\mathrm{PC}$ a related to PSA non-testing.

\section{Material and methods}

We analyzed data obtained concerning 2,567 men aged 65 years or more, and 332 men 55-59 years old, participants of the PolSenior population-based, multicenter, interdisciplinary study, conducted from 2007 to 2012. The study was designed to assess the health and socio-economic status of elderly individuals in Poland. It was based on a standardized questionnaire with elements of a comprehensive geriatric assessment, blood pressure and anthropometric measurements, and some blood and urine analyses [12]. The study protocol was approved by the Bioethics Commission (KNW-6501-38/I//08) and informed consent was obtained from each participant.

The questionnaire contained items concerning the participant's personal history of PCa treated with chemotherapy, radiotherapy, surgery, antiandrogens, or gonadotropin-releasing hormone $(\mathrm{GnRH})$ analogs, and PCa screening on the basis of PSA testing in the past.

Additionally, serum PSA levels were determined in the 2,122 elderly (> 65 years, 82.7\%) and 292 younger (55-59 years, 88.0\%) participants who agreed to venesection (Roche Diagnostics $\mathrm{GmbH}$; Mannheim, Germany for Roche Elecsys 2010 analyzer).

\section{Study questionnaire}

Previous PSA testing was determined by closed multiple-choice question (Have you ever had your PSA blood level tested? Once/more than once/ never/don't know or don't remember), supplemented by nurses on the basis of medical records held by the participants.

Prevalence of PCa was based on medical history and treatment for $\mathrm{PCa}$, including antiandrogenic drugs and $\mathrm{GnRH}$ analogs.

\section{Data analysis}

We included the following factors as potential determinants of PSA testing: nutritional status (based on body mass index (BMI), according to World Health Organization criteria), smoking status, alcohol consumption, place of residence (and city size), level of education, marital status, type 
of work in the past (office or manual worker), current personal income (low (below average income in the Polish population in 2008), median, or high (2 times higher than average)), independence as assessed by the Katz Activities of Daily Living (ADL) scale (disabled $<5$ points), and Instrumental Activities of Daily Living (IADL) as assessed by the Lawton scale (disabled < 24 points).

Measured serum PSA levels were stratified into 3 groups: $\leq 4,>4$ but $\leq 10$, and $>10 \mathrm{ng} / \mathrm{ml}$. Using the positive predictive value for PSA levels for detection of PCa in biopsy (32\% for PSA levels $>4.0$ [13]) we calculated the estimated prevalence of undiagnosed PCa in the entire Polish elderly population.

\section{Statistical analysis}

All statistical analyses were performed using SAS software version 9.1.3 (SAS Institute Inc., Cary, NC). Distribution of qualitative variables was shown by their absolute and relative frequencies. Distribution of quantitative variables was expressed as mean and standard deviation. Differences in the distribution of qualitative variables were analyzed using the $\chi^{2}$ test, and $p<0.05$ was considered significant in univariate analyses.
As the study sample had equal numbers in each age stratum, mean values in each stratum were weighted to allow for the actual age distribution in Poland. The standardized prevalence of $\mathrm{PCa}$ and undiagnosed PCa in the Polish elderly population (aged 65-74 years) in 2009 was calculated from these weighted means. Multivariate analysis of determinants of PSA testing was performed by logistic regression (Proc Logistic, SAS) with backward selection of explanatory variables. The dependent variable was PSA testing at any time in the past (yes/no) and the set of independent variables (complete model) including age, place of residence, education level, type of work, personal income, smoking habit, alcohol consumption, disability and nutritional status. All examined determinants were qualitative variables (definition in Table I). The results of multivariate analysis were interpreted using logistic odds ratios (and their $95 \% \mathrm{Cls}$ ), in addition to statistical significance of regression coefficients (criterion: $p<0.05$ ).

\section{Results}

\section{PSA testing in the past}

Two hundred eighty subjects (270 elderly, 10 aged 55-59 years) who did not respond clearly to

Table I. PSA testing according to age, socioeconomic factors, and other variables in elderly subjects in Poland. Results of univariate logistic regression analysis. OR values and $95 \%$ confidence intervals

\begin{tabular}{|c|c|c|c|c|c|}
\hline Variable & Level & $\begin{array}{c}\text { Univariate regression } \\
\text { OR }\end{array}$ & $P$-value & $\begin{array}{c}\text { Multiple backward } \\
\text { regression } \\
\text { OR }\end{array}$ & $P$-value \\
\hline \multirow[t]{5}{*}{ Age [years] } & $70-74$ vs. $65-69$ & $1.33(1.00-1.76)$ & 0.2 & - & - \\
\hline & $75-79$ vs. $65-69$ & $1.29(0.96-1.73)$ & & - & \\
\hline & $80-84$ vs. $65-69$ & $1.30(0.97-1.75)$ & & - & \\
\hline & $85-89$ vs. $65-69$ & $1.20(0.90-1.61)$ & & - & \\
\hline & $\geq 90$ vs. $65-69$ & $1.04(0.76-1.42)$ & & - & \\
\hline Residence & City vs. rural & $1.22(0.90-1.64)$ & 0.001 & - & - \\
\hline Marital status & Married vs. unmarried & $1.19(1.01-1.41)$ & 0.03 & $1.24(1.01-1.53)$ & 0.04 \\
\hline Education level & $\begin{array}{c}\text { Secondary/higher vs. } \\
\text { other }\end{array}$ & $2.27(1.85-2.71)$ & $<0.001$ & $1.49(1.16-1.91)$ & 0.001 \\
\hline Type of work & $\begin{array}{l}\text { Office worker vs. } \\
\text { manual worker }\end{array}$ & $2.42(2.00-2.93)$ & $<0.001$ & $1.37(1.09-1.71)$ & 0.005 \\
\hline Personal income & High/medium vs. low & $2.03(1.64-2.51)$ & $<0.001$ & $1.56(1.26-1.93)$ & $<0.001$ \\
\hline Smoking & No vs. yes & $2.25(1.73-2.93)$ & $<0.001$ & $2.06(1.54-2.78)$ & $<0.001$ \\
\hline $\begin{array}{l}\text { Alcohol } \\
\text { consumption }\end{array}$ & $\begin{array}{l}\text { No/seldom vs. } \\
\text { frequently }\end{array}$ & $1.35(1.11-1.64)$ & 0.002 & $1.28(1.03-1.60)$ & 0.02 \\
\hline \multirow[t]{2}{*}{ Disability } & ADL disability* vs. no & $0.61(0.47-0.80)$ & $<0.001$ & $0.58(0.39-0.85)$ & $<0.001$ \\
\hline & IADL disability vs. no & $0.69(0.50-0.79)$ & $<0.001$ & $0.66(0.50-0.86)$ & $<0.001$ \\
\hline Nutritional status & $\begin{array}{c}\text { Obese/overweight vs. } \\
\text { normal weight }\end{array}$ & $1.17(0.97-1.32)$ & 0.1 & - & - \\
\hline
\end{tabular}

${ }^{\star}$ Excluding disabled in $A D L$. 


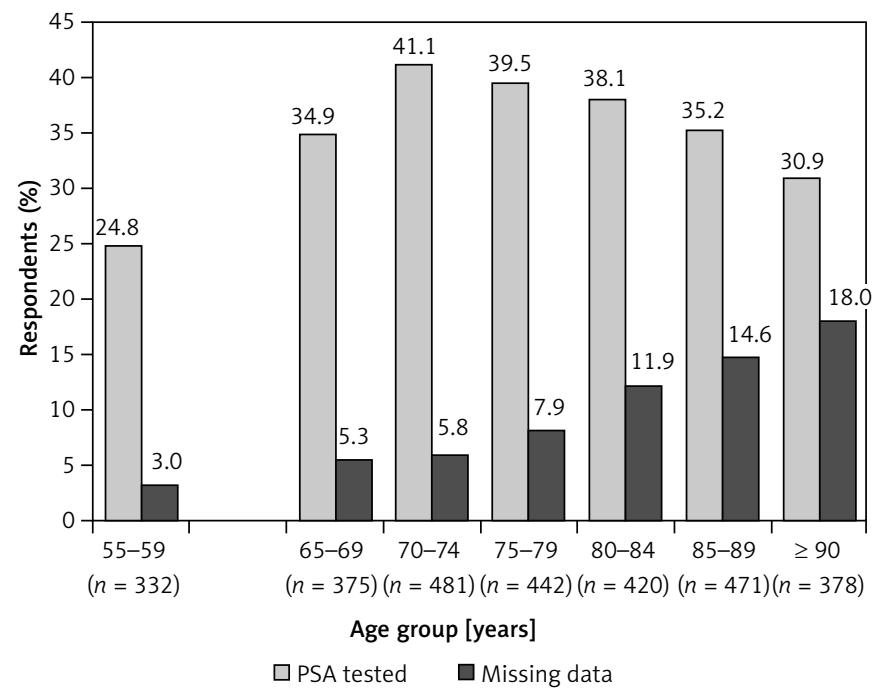

Figure 1. Prevalence of previous testing for PSA in elderly $(n=2567)$ and younger $(n=332)$ men in the PolSenior study

the questions were excluded from the analysis. Serum PSA had been previously tested in 947 of 2297 elderly (41.2\%) and only 80 of 322 participants aged $55-59$ years $(24.8 \%), p<0.001$ (Figure 1 ). In 539 (23.5\%) elderly and 31 (9.6\%) younger subjects, PSA had been tested more than once.

Therefore, $72.2 \%$ of younger men and $62.4 \%$ (weighted mean) of elderly ones aged 65-74 years had never been tested for PSA.

Prostate-specific antigen was tested most frequently in the 70-74 years age group (Figure 1). Factors associated with increased probability of previous PSA testing were residence in a city, being married, better educated, previous office employment, higher personal income, and independent in IADL (Tables I and II). Among IADL items, mode of transportation was strongly associated with probability of PSA testing $(\mathrm{OR}=0.57$ (0.45-0.71) for those who do not travel at all). In addition, PSA was more likely to be tested in overweight or obese men, nonsmokers, and those who consumed alcohol more than 3 times a week (Table II). The results of a backward model of multiple logistic regression analysis showed that the statistically significant determinants of PSA testing were current non-smoking status, disability, educational level, type of work in the past, personal income, marital status and pattern of alcohol consumption (Table I).

\section{Prostate cancer (PCa)}

Among the 2,567 elderly participants, 31 (1.3\%) were treated for PCa (calculated standardized prevalence rate in the elderly Polish population, 935 cases per 100,000 men). The percentage of subjects with PCa did not differ significantly across age groups. Men who consumed alcohol frequently were treated less often (Table I).
Among 332 younger participants (aged 55-59 years), 2 (0.6\%) were treated for PCa.

\section{PSA levels}

Prostate-specific antigen levels were elevated $(>4 \mathrm{ng} / \mathrm{ml}$ ) in 433 of the 2,122 elderly men tested (20.4\%), including 298 (14\%) with PSA 4-10 ng/ $\mathrm{ml}$ and 135 (6.4\%) with PSA > $10 \mathrm{ng} / \mathrm{ml}$. Among 292 younger participants tested, elevated PSA was found in 13 (4.5\%), including 10 (3.4\%) with PSA $4-10 \mathrm{ng} / \mathrm{ml}$ and 3 (1.0\%) with PSA > $10 \mathrm{ng} / \mathrm{ml}$ (Figure 2).

In the 415 elderly subjects, aged up to 75 years, who had not previously been treated for PCa or been tested for PSA, elevated serum PSA levels were observed in 53 (12.8\% of non-tested and $7.3 \%$ of the corresponding elderly study group). Of those 53 with elevated PSA, 41 had PSA 4-10 ng/ml and 12 had PSA > $10 \mathrm{ng} / \mathrm{ml}$. In the 242 younger subjects who had not previously been treated for PCa or tested for PSA, elevated serum PSA levels were observed in $13(5.2 \%$ of non-tested and $4.5 \%$ of the younger study group) - Figure 3.

Published data suggest that there is a $32 \%$ prevalence of $\mathrm{PCa}$ in patients who have not previously been treated for PCa and who have PSA > $4 \mathrm{ng} / \mathrm{ml}$ [13]. Assuming that this prevalence applied to our study population, we calculated that 4 of 13 aged 55-59 years, 8 of 24 aged 65-69 years, and 9 of 29 aged 70-74 years probably had undiagnosed PCa. Based on this, we calculated the prevalence of undiagnosed PCa in the population aged $55-59,65-69$ and $70-74$ years as 1370 , 2432 and 2244 cases per 100,000 population of men, while the standardized prevalence rate for elderly (aged 65-74 years) Polish men is 2352 cases per 100,000 population. 
Table II. Previous PSA testing and prevalence of prostate cancer according to age, socioeconomic factors, and other variables in elderly subjects in Poland

\begin{tabular}{|c|c|c|c|c|c|}
\hline Variable & Level & $\begin{array}{l}\text { Prior PSA testing } \\
(\%)\end{array}$ & $P$-value & $\begin{array}{c}\text { Prostate cancer } \\
(\%)\end{array}$ & $P$-value \\
\hline \multirow[t]{6}{*}{ Age [years] } & $65-69(n=375)$ & 34.9 & 0.03 & 0.5 & 0.3 \\
\hline & $70-74(n=481)$ & 41.1 & & 0.6 & \\
\hline & $75-79(n=442)$ & 39.5 & & 1.1 & \\
\hline & $80-84(n=420)$ & 38.1 & & 1.9 & \\
\hline & $85-89(n=471)$ & 35.2 & & 1.7 & \\
\hline & $\geq 90(n=378)$ & 30.9 & & 1.3 & \\
\hline \multirow[t]{3}{*}{ Residence } & Big city $(n=531)$ & 45.2 & $<0.001$ & 1.9 & 0.2 \\
\hline & City $(n=1016)$ & 38.7 & & 1.1 & \\
\hline & Rural $(n=991)$ & 30.1 & & 1.0 & \\
\hline \multirow{3}{*}{$\begin{array}{l}\text { Marital } \\
\text { status }\end{array}$} & Never married /divorced $(n=99)$ & 32.3 & 0.02 & 1.0 & 0.9 \\
\hline & Widowed $(n=650)$ & 33.0 & & 1.2 & \\
\hline & Married $(n=1730)$ & 38.6 & & 1.1 & \\
\hline \multirow{6}{*}{$\begin{array}{l}\text { Education } \\
\text { level }\end{array}$} & No education $(n=36)$ & 11.1 & $<0.001$ & 0 & 0.1 \\
\hline & Primary incomplete $(n=236)$ & 25.8 & & 0.4 & \\
\hline & Primary $(n=971)$ & 30.0 & & 0.9 & \\
\hline & Vocational $(n=435)$ & 36.6 & & 1.4 & \\
\hline & Secondary $(n=535)$ & 45.2 & & 1.5 & \\
\hline & Higher $(n=270)$ & 58.8 & & 1.5 & \\
\hline \multirow[t]{3}{*}{ Type of work } & Office worker $(n=641)$ & 52.5 & $<0.001$ & 1.8 & 0.09 \\
\hline & Manual worker $(n=1562)$ & 31.2 & & 0.8 & \\
\hline & Farmer $(n=253)$ & 34.7 & & 0.8 & \\
\hline \multirow{3}{*}{$\begin{array}{l}\text { Personal } \\
\text { income }\end{array}$} & Very low and low $(n=580)$ & 27.0 & $<0.001$ & 0.5 & 0.4 \\
\hline & Medium $(n=1238)$ & 38.4 & & 1.3 & \\
\hline & Higher $(n=335)$ & 53.1 & & 1.2 & \\
\hline \multirow[t]{2}{*}{ Smoking } & No $(n=2221)$ & 38.9 & $<0.001$ & 1.3 & 0.7 \\
\hline & Yes $(n=346)$ & 23.9 & & 0.9 & \\
\hline \multirow{3}{*}{$\begin{array}{l}\text { Alcohol } \\
\text { consumption }\end{array}$} & No $(n=605)$ & 34.8 & 0.009 & 1.6 & 0.05 \\
\hline & Seldom $(n=1285)$ & 39.6 & & 1.3 & \\
\hline & Frequently $(n=634)$ & 33.1 & & 0.5 & \\
\hline \multirow{2}{*}{$\begin{array}{l}\text { IADL } \\
\text { disability }\end{array}$} & No $(n=1794)$ & 40.7 & $<0.001$ & 1.3 & 0.6 \\
\hline & Yes $(n=708)$ & 27.4 & & 0.9 & \\
\hline \multirow{2}{*}{$\begin{array}{l}\text { ADL } \\
\text { disability }\end{array}$} & No $(n=2266)$ & 38.1 & $<0.001$ & 1.2 & 0.9 \\
\hline & Yes $(n=296)$ & 27.7 & & 1.0 & \\
\hline \multirow{4}{*}{$\begin{array}{l}\text { Body mass } \\
\text { index }\end{array}$} & Underweight $(n=39)$ & 20.0 & 0.01 & 0 & 0.1 \\
\hline & Normal weight $(n=683)$ & 34.3 & & 1.6 & \\
\hline & Overweight $(n=1081)$ & 39.0 & & 1.0 & \\
\hline & Obese $(n=619)$ & 39.3 & & 1.3 & \\
\hline
\end{tabular}

$A D L$ - activities of daily living, $I A D L$ - instrumental activities of daily living. 


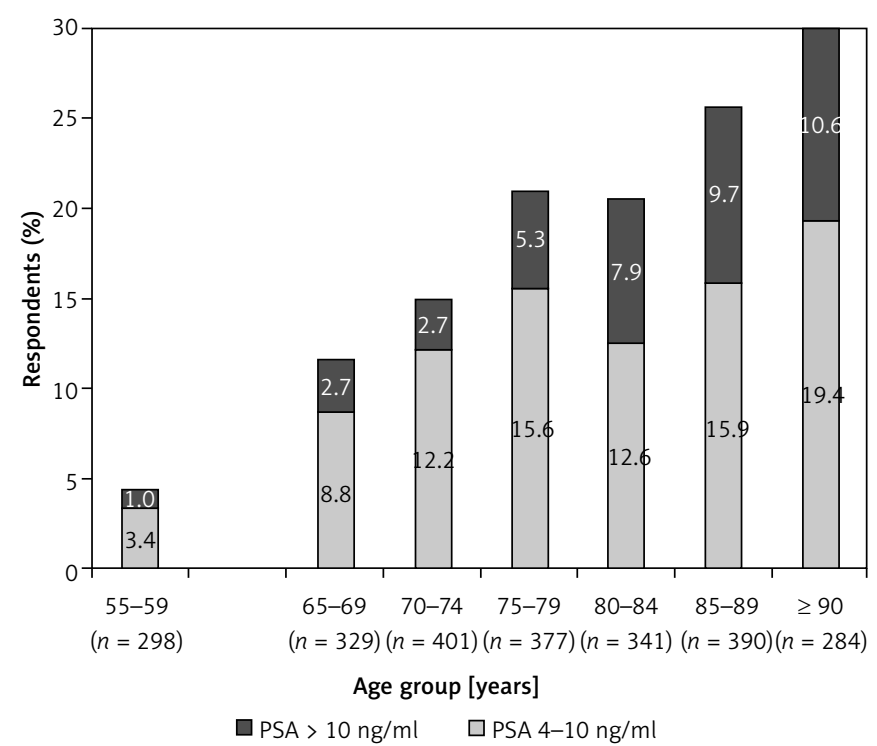

Figure 2. Percentage of participants with elevated PSA levels in the PolSenior study $(n=2414)$

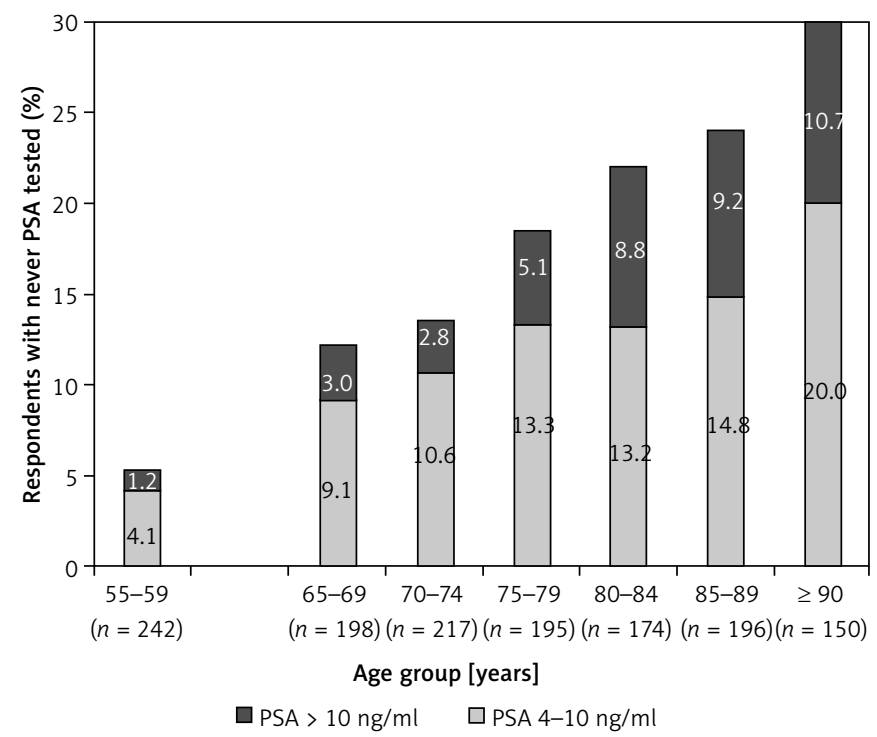

Figure 3. Percentage of participants with elevated PSA levels among those not treated for PCa and reporting no previous PSA tests $(n=1540)$ in the PolSenior study

\section{Discussion}

Our findings provide pertinent information regarding the frequency of PSA testing as well as prevalence of diagnosed and undiagnosed $\mathrm{PCa}$ in elderly Polish men. We were able to link these frequencies to socio-economic variables.

In the Polsenior study, $41.2 \%$ of elderly and $24.8 \%$ of men aged $55-59$ years had previously been tested for PSA. The utilization of PSA testing in the elderly Polish population has not previously been described. The only available data are from the Eurobarometer 66.2 "Health in the European Union" study, reporting PSA testing during the previous 12 months in 28 European countries, including Poland, in men aged 40 years or more [6]. The average proportion of the elderly population having had a PSA test was $22 \%$ for all countries, almost twice the proportion in Poland (12\%). The difference between the Eurobarometer 66.2 and the PolSenior study is related to their methodology. In the first one, only PSA tests performed within the previous 12 months were scored, while in the second there was no time limit to count the test.

The results of our study show that PSA screening in Poland is performed in one fourth (24.8\%) of men aged 55-59. The use of the test increases with age up to $41.1 \%$ of those aged $70-74$ years. The probability of having been tested for PSA is not related to the place of residence, but is strongly determined by socio-economic factors: better education, prior office work, higher than average personal income, as well as marital status, inde- 
pendence both in IADL and ADL, and self-care for own health (nonsmokers, nondrinkers). These sociodemographic data are partially in line with an Australian study reporting that current smokers were $15 \%$ to $20 \%$ less likely than those who have never smoked to undergo PSA testing [14]. Similarly, our results partly agree with the results of Eurobarometer 66.2 "Health in the European Union" reporting PSA testing during the previous 12 months in $15 \%$ of smokers and $25 \%$ of nonsmokers [6]. However, the results obtained in our study show a much stronger effect of marital status and education than reported in the European study [6]. Our results demonstrate lower rates of PSA testing by disabled elderly men. The effect of impaired IADL without impairment in ADL was associated with lower rates of PSA testing. This association has not been reported previously.

The PolSenior study shows that $62.4 \%$ (weighted mean) of elderly men aged 65-74 years and $72.2 \%$ of younger ones had never been tested for PSA. In the oldest groups, the low rate of screening can be explained by the restricted availability of PSA testing more than 2 decades ago. In younger men, the explanation is more likely to be due to poor self-care and low utilization of preventive medical services.

It has already been shown that serum PSA concentrations in excess of the median for that age group better predict PCa than family history or race [15]. Thus, annual PSA tests are recommended in men aged 40-75 years [16]. However, the predictive value of elevated total PSA for cancer decreases with age, because of the increasing prevalence of benign prostate hyperplasia (BPH) in elderly men $[17,18]$.

Additionally, it should be stressed that the benefits of early detection of PCa decrease with age because of the long natural history of PCa [19]. Thus routine PSA screening in men older than 75 years does not appear to be beneficial. American guidelines recommend this procedure only for men in very good health with a family history of longevity, who are therefore likely to live at least another 10 years [11]. Even in these patients, PCa management should generally be limited to observation, with treatment offered only in aggressive cases.

Rapid dissemination of PSA screening and easier access to transrectal ultrasound and prostate biopsy allows for early diagnosis of PCa and implementation of radical therapy. The PCa diagnoses have increased substantially in Poland since the early 1990 s. More than $70 \%$ of PCa cases and almost $90 \%$ of deaths due to PCa occur in men older than 65 years. However, mortality from PCa has not risen since the mid 1990s, due to earlier and more effective treatment [20]. The majority of PCas, including curable cases, are diagnosed in men with PSA levels less than $10.0 \mathrm{ng} / \mathrm{ml}$, in the so-called "gray zone" $[13,21]$. Our study demonstrated that approximately $7 \%$ of Polish elderly aged 65-74 years with PSA levels > $4.0 \mathrm{ng} / \mathrm{dl}$ had not previously been tested, and according to guidelines most of them (having considered the doubtful advantage in those with significant co-morbidity and poor health) should be referred to urologists for further assessment. This includes one fifth of subjects with PSA levels over $10.0 \mathrm{ng} /$ $\mathrm{dl}$, expected to have about $50 \%$ risk of $\mathrm{PCa}$.

Our findings complement data provided by the National Cancer Center on the incidence and mortality of PCa in Poland $[4,20]$ by adding an estimation of PCa prevalence in the elderly. As was estimated in our study, the standardized prevalence rate of diagnosed (and treated) PCa in elderly men was 935 per 100,000 population. As could be expected, this value is much higher than the standardized incidence rate for this age group reported by the National Cancer Center in 2009 (322.2 per 100,000 population) [4]. However, the small number of respondents with a history of PCa in this study $(n=31)$ precludes a more detailed epidemiological analysis, including nutritional status [22].

Our data show that further increases in the incidence as well as in the prevalence of diagnosed PCa in the future can be expected. Presented results of PSA tests revealed a large group of respondents who probably had undiagnosed PCa. Elevated PSA level (> $4 \mathrm{ng} / \mathrm{ml}$ ) was found in $4.5 \%$ of younger and $7.3 \%$ of elderly (aged $65-74$ years) participants of the PolSenior study who had not previously had a PSA test. Assuming the $32 \%$ risk of PCa in these individuals [13], we estimated the prevalence of undiagnosed PCa as 1370 cases per 100,000 population of 55-59-year-old, and 2352 cases per 100,000 population of 65-74-year-old elderly Polish men.

Our calculations, even assuming their overestimation, suggest that the prevalence of undiagnosed PCa in the youngest population of Polish elderly is higher than that of diagnosed elderly patients (935 vs. 2352 cases per 100,000 population).

Our study has certain limitations related to the methodology of large population-based surveys assessing multidimensional aspects of health in the elderly and the self-reported nature of many data. The interview did not include questions about whether PSA tests were initiated by a doctor or the subject himself, or the time of PSA testing. Additionally, the estimation of underdiagnosed PCa is based on data from a different ethnic population. However, there is a lack of other studies showing the risk of PCa in elderly men in relation to PSA. 
It should be stressed that PSA and DRE remain the best documented screening tools. Genetic methods for identification of the population at risk are still beyond the horizon [23], even if heritable factors account for more than fifty percent of PCa [24].

In conclusion, in Poland, only $41.2 \%$ of older men have ever had a PSA test. Characteristics of those more likely to be tested for PSA include functional independence, being married, better educated, previous office employment, higher than average personal income and a healthy lifestyle (nonsmoker). Our data suggest substantial underdiagnosis of prostate cancer among Polish men.

\section{Acknowledgments}

This study was implemented under the publicly funded project no. PBZ-MEIN-9/2/2006, Ministry of Science and Higher Education.

We thank Prof. James Tattersall, MD, Ph.D. for his invaluable editorial help during the preparation of this manuscript.

\section{Conflict of interest}

The authors declare no conflict of interest.

\section{References}

1. Ferlay J, Steliarova-Foucher E, Lortet-Tieulent J, et al. Cancer incidence and mortality patterns in Europe: estimates for 40 countries in 2012. Eur J Cancer 2013; 49: 1374-403.

2. Jemal A, Siegel R, Xu J, Ward E, Forman D. Cancer statistics, 2010. CA Cancer J Clin 2010; 60: 277-300.

3. Ilic D, O'Connor D, Green S, Wilt TJ. Screening for PCa: an updated Cochrane systematic review. BJU Int 2011 ; 107: 882-91.

4. National Cancer Centre Report. Available at: http:// 85.128.14.124/krn/

5. Didkowska J, Wojciechowska U, Zatonski W. [Malignant tumors of the prostate gland. In: Predictions for morbidity and mortality from cancer in Poland [Polish]. Institute of Oncology, Warsaw 2009; 69-74.

6. Burns R, Walsh B, O'Neill S, O'Neill C. An examination of variations in the uptake of PCa screening within and between the countries of the EU-27. Health Policy 2012; 108: 268-76.

7. Duffy MJ. PSA in screening for prostate cancer: more good than harm or more harm than good? Adv Clin Chem 2014; 66:1-23.

8. Hugosson J, Carlsson S. Overdetection in screening for prostate cancer. Curr Opin Urol 2014; 24: 256-63.

9. Roobol MJ, Kranse R, Bangma $\mathrm{CH}$, et al. Screening for prostate cancer: results of the Rotterdam section of the European randomized study of screening for prostate cancer. Eur Urol 2013; 64: 530-9.

10. Carter HB. American Urological Association (AUA) guideline on prostate cancer detection: process and rationale. BJU Int 2013; 112: 543-7.

11. U.S. Preventive Services Task Force: Screening for PCa: U.S. Preventive Services Task Force Recommendation Statement. Ann Intern Med 2008; 149: 185-91.
12. Bledowski P, Mossakowska M, Chudek J, et al. Medical, psychological and socioeconomic aspects of aging in Poland: assumptions and objectives of the PolSenior project. Exp Gerontol 2011; 46: 1003-9.

13. Catalona WJ, Richie JP, Ahmann FR, et al. Comparison of digital rectal examination and serum prostate specific antigen in the early detection of PCa: results of a multicenter clinical trial of 6,630 men. J Urol 1994; 151 : 1283-90.

14. Jorm LR, Shepherd LC, Rogers KD, Blyth FM. Smoking and use of primary care services: findings from a population-based cohort study linked with administrative claims data. BMC Health Serv Res 2012; 12: 263.

15. Loeb S, Roehl KA, Antenor JA Catalona WJ, Suarez BK, Nadler RB. Baseline prostate-specific antigen compared with median prostate-specific antigen for age group as predictor of PCa risk in men younger than 60 years old. Urology 2006; 67: 316-20.

16. Loeb S, Catalona WJ. Prostate-specific antigen in clinical practice. Cancer Lett 2007; 249: 30-9.

17. Morgan TO, Jacobsen SJ, McCarthy WF, Jacobson DJ, McLeod DG, Moul JW. Age-specific reference ranges for prostate-specific antigen in black men. N Engl J Med 1996; 335: 304-10.

18. Prajsner A, Chudek J, Szybalska A, Piotrowicz K, Zejda J, Więcek A. Socioeconomic profile of elderly Polish men treated for benign prostate hyperplasia: results of the population-based PolSenior study. Eur Geriatr Med 2015; 6: 53-7.

19. Ross KS, Guess HA, Carter HB. Estimation of treatment benefits when PSA screening for PCa is discontinued at different ages. Urology 2005; 66: 1038-42.

20. Wojciechowska U, Didkowska J, Zatonski W. Cancers in Poland in 2008 [Polish]. National Cancer Centre, Warsaw 2010; 38-40.

21. Vickers AJ, Sjoberg DD, Ankerst DP, Tangen CM, Goodman PJ, Thompson IM Jr. The PCa Prevention Trial risk calculator and the relationship between prostate-specific antigen and biopsy outcome. Cancer 2013; 119 : 3007-11.

22. Golabek T, Powroźnik J, Chłosta P, Dobruch J, Borówka A. The impact of nutrition in urogenital cancers. Arch Med Sci 2015; 11: 411-8.

23. Zuo L, Zhang LF, Wu XP, et al. Association of a common genetic variant in prostate stem cell antigen with cancer risk. Arch Med Sci 2014; 10: 425-33.

24. Demichelis F, Stanford JL. Genetic predisposition to prostate cancer: update and future perspectives. Urol Oncol 2015; 33: 75-84. 